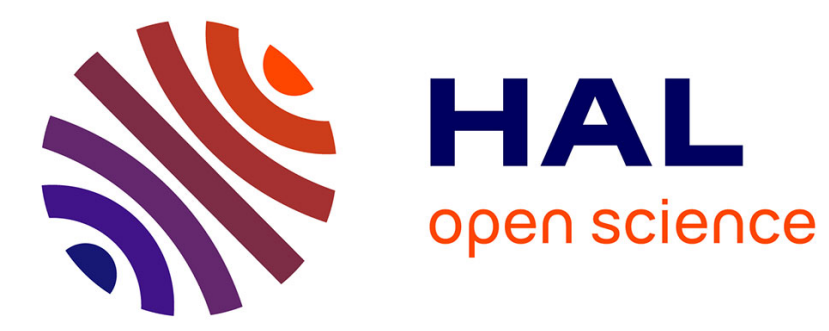

\title{
Wall Heat transfer correlation for rotary kiln with secondary air flow and recycled materials inlet
}

\author{
Laurédan Le Guen, Florian Huchet, Jean Dumoulin
}

\section{To cite this version:}

Laurédan Le Guen, Florian Huchet, Jean Dumoulin. Wall Heat transfer correlation for rotary kiln with secondary air flow and recycled materials inlet. Experimental Thermal and Fluid Science, 2014, 54, pp. 110-116. 10.1016/j.expthermflusci.2014.01.020 . hal-01016542

\section{HAL Id: hal-01016542 \\ https://hal.science/hal-01016542}

Submitted on 30 Jun 2014

HAL is a multi-disciplinary open access archive for the deposit and dissemination of scientific research documents, whether they are published or not. The documents may come from teaching and research institutions in France or abroad, or from public or private research centers.
L'archive ouverte pluridisciplinaire HAL, est destinée au dépôt et à la diffusion de documents scientifiques de niveau recherche, publiés ou non, émanant des établissements d'enseignement et de recherche français ou étrangers, des laboratoires publics ou privés. 


\section{Accepted Manuscript}

A wall heat transfer correlation for the baffled-rotary kilns with secondary air flow and recycled materials inlet

Le Guen Lauredan, Huchet Florian, Dumoulin Jean

PII:

$$
\text { S0894-1777(14)00029-6 }
$$

DOI: http://dx.doi.org/10.1016/j.expthermflusci.2014.01.020

Reference: ETF 8146

To appear in:

$$
\text { Experimental Thermal and Fluid Science }
$$

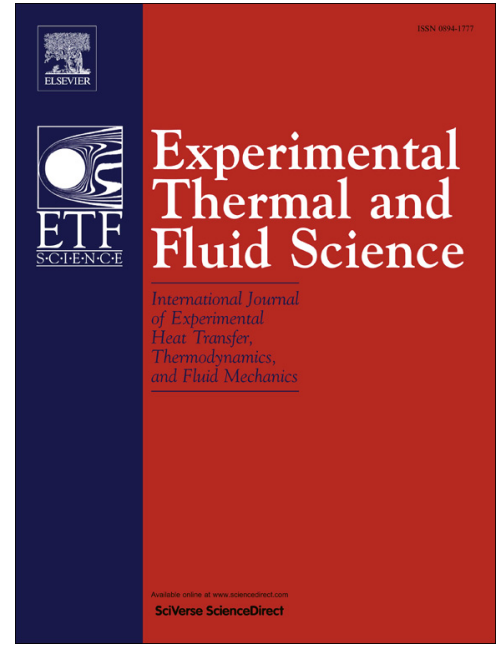

Received Date:

12 August 2013

Revised Date:

22 January 2014

Accepted Date:

22 January 2014

Please cite this article as: L.G. Lauredan, H. Florian, D. Jean, A wall heat transfer correlation for the baffled-rotary kilns with secondary air flow and recycled materials inlet, Experimental Thermal and Fluid Science (2014), doi: http://dx.doi.org/10.1016/j.expthermflusci.2014.01.020

This is a PDF file of an unedited manuscript that has been accepted for publication. As a service to our customers we are providing this early version of the manuscript. The manuscript will undergo copyediting, typesetting, and review of the resulting proof before it is published in its final form. Please note that during the production process errors may be discovered which could affect the content, and all legal disclaimers that apply to the journal pertain. 


\title{
A wall heat transfer correlation for the baffled-
}

\section{rotary kilns with secondary air flow and}

\section{recycled materials inlet}

\author{
Le Guen Lauredan*, Huchet Florian, Dumoulin Jean \\ LUNAM, University of Nantes, IFSTTAR, Route de Bouaye, BP 4120, 44341 \\ Bouguenais Cedex, France \\ *corresponding author / email: lauredan.leguen@ifsttar.fr
}

\begin{abstract}
:
The increasing use of the baffled-rotary kiln equipment in many innovative materials processing industrial applications suggests examining the heat transfer phenomena in order to improve the multi-phase flow modeling tools. Their development and use will be relevant for tackling the current energy issues. The heat transfer models available for the rotary kiln in the literature are, for now, not enough efficient for the baffled-rotary kiln case.

The present paper is aimed at suggesting a wall heat transfer correlation for the rotary kilns with the secondary inlet. The experimental thermal data acquired within large-scale rotary drum applied to the asphalt concrete materials production, are remained in order to give rise the new issues. These latter results are connected to a visualization campaign performed at the pilot-scale in order to assess the transversal distribution of the granular phase materials. Their analysis suggests a more appropriate physical modeling of the wall heat transfer path. It leads to transform the classical correlation of type $N u=\mathrm{f}(\operatorname{Re}, P r)$ in a new expression of type
\end{abstract}


$N u=\mathrm{f}(R e, S t)$ based on a new physical modeling inventory corresponding to the hot and cold fluxes flowing within the baffled-rotary kiln. Thus, the major modification is based on the introduction of the Stanton $(S t)$ number in the wall heat transfer correlation. This expression is found more convenient for the baffled-rotary kiln application. This new expression is validated by the comparison with the experimental Nusselt numbers calculated from the inner heat transfer measurements coefficient measured in the baffled-rotary kiln performed at large scale.

Key-words: Heat transfer; materials processing; Nusselt number; baffled-rotary kiln

\section{Introduction}

Rotary kiln processes are widely applied to many products of chemical, food and materials industry including mineral, metallurgical or waste processing [1]. The capability to treat large amount of materials makes the rotary drum a convenient gas/solid reactor with intensive heat and mass transfer.

The rotary kiln can operate by external heating in the case of organic matter treatment [2] or gasification [3], or by internal heating for mineral materials processing [4]. The rotary kiln is generally a slightly inclined drum equipped with a burner. The burner releases sufficient energy for the heat treatment. The extraction of the moisture can involve many technologies (atomization, flash dryer, fluidized bed) used in many important manufacturing sectors (minerals, polymers, paper). In the case of road and pavement industry, the rotary drum dryer (or rotary kiln) (see figure 1) is the most appropriated continuous process in order to reach high materials feed rate, and to accomplish successive operations of drying, heating, mixing and coating with the bituminous binder for the asphalt concrete production. 
The knowledge of the physical mechanism occurring within the rotary kiln is crucial in order to optimize the industrial plant [5]. Thus, many scientific papers have emerged since about thirty years. Their contributions were significant in the heat transfer characterization at the inner wall of the drum based on the Tsheng \& Watkinson [6] works until recent studies of Herz [7]. Yet, except the work of Gorog [8] no results from these papers were really applied to the large-scale furnace. Indeed, the industrial furnace, as explained above, works with hot gases where convective mechanisms are significant. Most of the scientific researches were performed in rotary drum without hot exhaust gases. Even if the particles motion can play a significant role on the heat transfer [9] [10] [11], as already proposed by the pioneers such as Miller et al. [12], it remains difficult to distinguish the predominant transfer phenomena in multi-phase flows. The heat transfer between the gaseous and granular phases and the wall of the baffled-rotary kiln can take place by convection, conduction and radiation. However, the inner parietal heat transfer nevertheless remains as limiting parameters for the innovative rotary kiln design.

Thus, many recent studies [13] [14] [7] were focused on this physical phenomenon in order to validate the most popular solid to wall heat transfer models also called " penetration models" [6] [15]. Most of them predicted quite well the solid/wall transfer coefficient in rotary kiln in laboratory tumbler with sand materials.

Yet, no work studied the actual case taking into account both the solid-to-wall heat transfer and the gases-to-wall heat transfer. These two heat transfer modes are localized at specific areas of the inner drum wall (figure 2).

Predicting the relative importance of each parietal heat transfer mode remains a large difficulty in industrial rotary kiln. For this purpose, the present paper considering experimental data obtained in two complementary rotary drums, proposes a new correlation of the wall heat transfer for the rotary kilns. 
Section 2 describes the measurements performed at large-scale [16] and summarizes the main aero-thermal characteristics. They imply a sketch of the multiphase flow influencing the heat transfer paths. Section 3 is dedicated to the characterization of the granular dynamics based on a set of snap-shot images captured from a camera in the cross-section at a pilotscaled drum. Section 4 presents an expression based on the Nusselt number characterizing the inner wall heat transfer in a baffled-rotary drum. Introduced the work by Colburn et al. [17] for the straight channel case, its modification leads to the introduction of the Stanton $(S t)$ number due to the numerous heat transfer paths. These calculated Nusselt $(\mathrm{Nu})$ numbers from the new correlation are compared with the experimental $\mathrm{Nu}$ numbers obtained by the experimental measurements at large-scale [16] in order to evaluate the validation of this correlation in its range of validity.

\section{Aggregates rotary kiln at large-scale}

The characterization of convective heat transfer path in an industrial aggregates rotary kiln was performed. The baffled-rotary kiln applied to the road pavements production, so called HMA (HMA: Hot Mix Asphalt), is a highly energy-intensive process involving three manufacturing stages: drying, heating and mixing with a bituminous binder. Indeed, it is necessary to heat the aggregates at a temperature ranged between $100^{\circ} \mathrm{C}$ and $150^{\circ} \mathrm{C}$ in order to decrease the viscosity of the mixture to obtain the desired workability during the setup of the asphalt material.

Namely, the aggregates are conveyed within the slightly titled rotary drum. It is equipped by the baffles, which generate a cascading regime of the aggregates. The granular behavior ensures the drying and heating stages by promoting the contact with the hot gases. The hot gases are provided by a burner located at the inlet of the drum. 
In addition, the Recycled Materials Inlet (RMI) is designed to add the recycled asphalt pavement required for the specific HMA composition. However, the dust collecting is ensured by a depression generated by a draught fan. Consequently, the non controlled and non monitored air jet penetrations are occurred from this inlet. Thus, any multi-holes such as the recycled materials inlet can exert a secondary air flow disturbing the performance of the kiln.

Four productions were planned in an industrial aggregates rotary kiln [16] in order to establish an experimental campaign based on the thermal characterization at several location of the drum. In the inner part, a rod composed of seven thermal probes (K-type) was positioned while the apparent temperatures of the external shell were captured by a thermal Infra-Red Camera. The gases flow rates were also measured at three positions of the plant.

These datasets were processed in order to assess the longitudinal heat transfer coefficient, $h_{i}$, corresponding to the heat exchange between the multi-phase flow (including the particulate system and the freeboard gases) and the inner wall of the drum. An accurate explanation of this experimental study is available in the work of Le Guen et al. [16] where the comparison with existing correlations corresponding to forced convection in straight channels [18] and those derived from an external heating in rotary drum [9] are analyzed. Indeed, no one corresponds to the industrial rotary kiln where the exhaust hot gases and the granular motion simultaneously occur within the equipment.

As shown in figure 3 , the inner heat transfer coefficient, $h_{i}$, corresponds to a value ranging from $15 \mathrm{~W} \cdot \mathrm{m}^{2} \cdot \mathrm{K}^{-1}$ to $150 \mathrm{~W} \cdot \mathrm{m}^{2} \cdot \mathrm{K}^{-1}$ in the heating zone of the drum. The gases temperature decreases in the upstream area of the heating zone, then the gases are refreshed by the air jet penetration at the ambient temperature from the RMI. The external wall is also concerned by the cooling at the same location $(z=5.4 \mathrm{~m})$ as depicted in the figure 4 . It can be attributed to the aero-thermal phenomenon caused by the hole used for the recycled materials. This secondary air flow approximately corresponds to $60 \%$ of the total gases mass balance 
flowing through the drum. The gases flow rates into the rotary drum are modified with a substantial increase of the Reynolds number from about 80,000 to about 400,000 [16].

The chart of the figure 4 shows an important rise of $h_{i}$. Between the RMI and the bitumen injection, $h_{i}$ increases from about $40 \mathrm{~W} \cdot \mathrm{m}^{-2} \cdot K^{-1}$ to $120 \mathrm{~W} \cdot \mathrm{m}^{-2} \cdot \mathrm{K}^{-1}$. This rise demonstrates an intensification of the wall heat transfer. So, the thermal losses across the drum wall are more important in this specific drum field. This phenomenon is probably due to the wall cooling detected by the wall temperature decrease.

Thus, the analogy with the hole-cooling generated by the injection of cold air can be made $[19,20]$. Indeed, the evolution of each flow (cold and hot sources) can be considered in the thermal balance in order to better predict the local longitudinal wall heat transfer coefficient according to the multi-phase system. In order to achieve this objective, the hot mass flow and the cold mass flow need to be considered according to the position along the rotary drum.

In addition, the design of the drum induces the modifications of the mass flow rate for the two flowing phases. Indeed, the secondary air flow generates two major modifications. It disturbs the aero-dynamical flow pattern of the gases. It implies another thermal balance because this flow is considered as a cold flow. Consequently, the distribution of heat transfer is depending on the composition of these two flows.

A scheme describing the different mass flow rates according to their source (hot or cold) is proposed in the figure 5.

On the basis of this scheme, one can define the ratio distributing the heat transfer paths between the cold and hot flows. The numerator of this ratio is the cold mass flow rate weighted by its specific heat. The denominator of this ratio is equal to the hot mass flow rate 
weighted with its specific heat. The evolution of the different mass flow rate can be taken into account in the system with a ration equal to:

$$
\frac{m_{c} \cdot C_{p_{c}}}{m_{h} \cdot C_{p_{h}}}
$$

with $\dot{m}_{c}$ and $C_{p c}$ being respectively the cold mass flow rate and the specific heat of the cold source, and $\dot{m}_{h}$ and $C_{p h}$ being the hot mass flow rate and the specific heat of the hot source. This ratio is depending on the axial location within the rotary kiln. Thus, before the RMI, it is given by:

$$
\frac{\dot{m}_{c} \cdot C_{p_{c}}}{m_{h} \cdot C_{p_{h}}}=\frac{\dot{m}_{a} \cdot C_{p_{a}}}{m_{g} \cdot C_{p_{g}}}
$$

where $\dot{m}_{a}$ and $C_{p a}$ are respectively the mass flow rate and the specific heat of the aggregates, and $\dot{m}_{g}$ and $C_{p g}$ are respectively the mass flow rate of the hot gases provided by the burner and its specific heat.

After the RMI, this ratio is modified as follows:

$$
\frac{m_{c} \cdot C_{p_{c}}}{m_{h} \cdot C_{p_{h}}}=\frac{m_{a} \cdot C_{p_{a}}+m_{R M I} \cdot C_{p_{R M I}}}{m_{g} \cdot C_{p_{g}}}
$$

with ${ }_{m_{R M I}}$ the mass flow rate of the air jet penetration and $C_{p R M I}$ its specific heat. The specific heat of aggregates, $C_{p a}$, and that of air, $C_{p g}$, and $C_{p R M I}$, are taken from the literature [21] [22].

\section{Granular dynamics}

\subsection{Pilot-scale drum}


The experimental campaign at pilot scale of an industrial unit was carried out in order to observe the distribution of the aggregates in the cross-section of the drum without gas flow (figure 6). The first objective of the visualization is aimed at setting the physical basis of the transfer phenomena inside the drum from the knowledge of the mixing granular media. Indeed, the baffles influence the transport of solids, as mentioned by Huang et al. [23]. Thus, a good knowledge of the granular flow is fundamental to set the right assumption for the heat transfer modeling.

The experiment was carried out on a pilot-scaled rotary drum without burner. This device was originally designed for the understanding of the mechanical running of the asphalt plant (ex. rotation setting of rotary drum). This experiment was performed within the drum in a specific field, which is bounded by a circular Plexiglas wall and a circular cardboard wall painted white in order to improve the contrast with the black beads and its detection. Their diameter is equal to $552 \mathrm{~mm}$, which is the inner diameter of the rotary drum. The width of the working area is equal to $140 \mathrm{~mm}$.

A time-resolved camera was chosen to capture instantaneous image. The system includes a DALSA FA-20-01M1H camera $(100 \mathrm{~Hz}$ at a resolution of $1400 \times 1024$ pixels). A dedicated processor, STEMMER IMAGING, was used to acquire data and thus to process each image. The frequency of the camera is adjusted to $20 \mathrm{~Hz}$ in order to keep a compromise between spatial resolution and temporal accuracy. The effect of the perspective view and of the parallax phenomenon had been reduced by the position of the camera. It was positioned in the longitudinal axis of the circular working area. The black spherical steel beads are used as particles with average sizes of $6 \mathrm{~mm}$ and their density close to $7.8 \mathrm{~g} . \mathrm{dm}^{-3}$. There were 4450 beads used for this experiment, and the fill rate was fixed to $13 \%$ in the field of the drum. 
The experiments were carried out at a rotation speed equal to $18 \mathrm{rpm}$. The Froude number $\left(F r=\frac{\frac{D_{i}}{2} \cdot \omega^{2}}{g}\right.$ with $\omega$ he rotation speed and $g$ the gravity force) is equal to 0.01 and the granular flow regime corresponds to rolling regime in smooth drum [24]. The horizontal setting and the containment of the working area led to obtain only the forces induced by the baffles action and the gravity action applied to the steel beads. Thus, they only moved transversally, and this experiment can be considered as a 2-D experiment.

\subsection{Granular motion at a pilot-scaled drum}

The granular motion at the pilot-scaled drum was observed. The observation is based on the visualization performed by the experimental set-up described above. For example, the figure 8 is a typical image extracted to the visualization. All images are extracted and analyzed. This analysis is realized in three steps for each image. The first one is a contrast adjusting (by the means of the ImageJ software [25]) in order to improve the detection of the black steel balls constituting the aerated granular phase. The second one is an inventory of the black steel balls. The third one is the calculation of the relative distribution of the steal beads between the dense and aerated phase.

Two major results are deduced by this experimental campaign at the pilot scale. The first concerns the transversal distribution of the granular phase. The analysis of the visualization led to obtain the measurement of the relative distribution of the aerated phase, which was equal to $4 \%$ of the whole mass (figure 9). Debacq [26] already confirms this value. Even if the aerated phase is preponderant for the gas-to-solid heat transfer path, this phase is less preponderant for the wall heat transfer pattern. Thus, $96 \%$ of the solids particles are involved in the heat transfer with the drum wall, located in the bottom of the drum and into the baffles. 
The second result regards the wall heat transfer paths. The available pictures show the separation between the gaseous phase and the particulates phase. Assuming a continuous contact between the wall and the granular bed, a convective mechanism occurs a heat transfer between solids particles and the inner drum wall. One can consider that the gaseous and the granular phases are divided in the cross-section (see figure 6). Thus, two characteristic lengths are defined. One, $l_{b w}$, corresponds to the heat transfer between the granular bed and the inner wall of the drum. The second, $l_{g w}$, corresponds to the heat transfer between the gas and the inner wall of the drum.

The determination of these two lengths is based on the geometrical formulation with some assumptions [27]. Indeed, the two length of contact involved in the heat transfers mentioned above, are calculated from the following equations:

$$
\begin{aligned}
& l_{b w}=\theta \cdot \frac{D_{i}}{2} \\
& l_{g w}=(2 \cdot \pi-\theta) \cdot \frac{D_{i}}{2} \\
& \frac{D_{i}^{2}}{8} \cdot(\theta-\sin \theta)=\frac{\rho_{b}}{v_{a}} \cdot m_{a}
\end{aligned}
$$

with $D_{i}$ the inner drum diameter of the baffled-rotary kiln, $m_{a}$ the mass flow rate of the aggregates used for the HMA manufacturing, $v_{a}$ the velocity of the aggregates composing the granular bed and $\beta$ the density of the granular bed. However, these two heat transfers occur on the inner perimeter. Thus, the characteristic length used for the Nusselt number and for the evaluation of $h_{i}$ is the inner perimeter of the rotary drum:

$$
\pi \cdot D_{i}=l_{b w}+l_{g w}(7)
$$

Thus, $N u$ is defined by: 


$$
N u=\frac{h_{i} \cdot \pi \cdot D_{i}}{\lambda}
$$

with $\lambda$ the conductivity of the multi-phase flow. This latter thermal physical parameter is being balanced by each mass flow rate constituting the multi-phase flow such as:

$$
\lambda=\frac{1}{m_{a}+m_{g}} \cdot\left(m_{a} \cdot \lambda_{a}+\dot{m}_{g} \cdot \lambda_{g}\right)
$$

with $m_{g}$ the mass flow rate of hot gases, $\lambda_{t}$ the conductivity of these aggregates, $\lambda_{g}$ the conductivity of the hot gases. Consequently, the Nusselt number is given by:

$$
N u=\frac{h_{i} \cdot \pi \cdot D_{i}}{\frac{1}{m_{a}+m_{g}} \cdot\left(m_{a} \cdot \lambda_{a}+m_{g} \cdot \lambda_{g}\right)}
$$

Thus, the dimensionless expression linked to the $h_{i}$ determination corresponds the two heat transfer between the granular bed and the inner wall and the heat transfer between the gas and the inner wall. Their respective weight is taken account trough the mass flow rate of each flowing phase.

\section{Wall heat transfer correlation in rotary kiln}

This section is aimed at presenting the Nusselt number correlation necessary expressed to evaluate the inner parietal heat transfer in the baffled-rotary kiln. As for straight duct geometry established by the work of Colburn et al. [17], this correlation is adapted to the continuous medium flowing adjusted for the baffled-rotary drum which is used for the HMA production then compared to the experimental measurements performed on the continuous cocurrent HMA plant [16]. 
The inner parietal heat transfer within the baffled-HMA rotary drum is induced by the temperature difference between (i) the gases and the aggregates flows, and, (ii) and the temperature between the two-phase flow (gases and aggregates) and the drum wall. Moreover, the length of the drum needs to consider the system as non-established. Considering the correlation of Colburn for a non-established flow in turbulent regime in straight duct [17], we have according to the following expression:

$$
N u_{\text {calc }}=0.023 \cdot \operatorname{Re}^{0,8} \cdot \operatorname{Pr}^{0,3} \cdot\left(1+\left(\frac{D_{i}}{z}\right)^{0,7}\right)
$$

with $R e$ is the Reynolds number, $\operatorname{Pr}$ the Prandtl number and $z$ the axial position.

Thus, the Colburn correlation requires modification in order to be used in the case of the HMA baffled-rotary drum by taking into account:

- theses modifications are required by the physical composition of the multi-phase species flowing within the drum,

- the transversal repartition of the gases and the aggregates observed at pilot scale, and the various mass fluxes mentioned above.

Firstly, the Prandtl number, adapted for gases and liquid, is not appropriate in our case since the two phase nature flowing within the drum are gases and solids (or aggregates). The use of the Stanton $(S t)$ number for the wall heat transfer characterization appears more suitable. Indeed, the $S t$ number characterizes the ratio between the global heat exchanged convective heat into the thermal capacity of the medium. Thus, the wall heat transfer distribution between the involved phases can be distinguished in such way that the heat transfer distribution between the involved phases. In the HMA rotary kiln, the thermal heat provided by the hot gases $\left(v_{g} \cdot \rho_{g} \cdot C_{p_{g}}\right)$ is yielded to the convective exchange $\left(h_{i}\right)$ heat is that between the two-phase flow and the drum wall, and the global heat is provided by the hot 
gases. Consequently, the use of the $S t$ number is presently adequate to its application, since each wall heat transfer contributions is indirectly taken into account according to the following expression:

$$
S t=\frac{h_{i}}{v_{g} \cdot \rho_{g} \cdot C_{p_{g}}}
$$

with $h_{i}$ the inner global heat transfer coefficient obtained by the experimental campaigns [16], $\rho_{g}$ the density of hot gases, $C_{p g}$ the specific heat of hot gases and $v_{g}$ the actual gas velocity in the volume on the top of the granular bed. This velocity is depending on the gases mass flow rate and the air density, which is depending on the hot gases temperature.

Secondly, this Nusselt number correlation must take into account the influence of each phase flowing within the drum. It is characterized by the ratio defined by the equations (1), (2) and (3).

Finally, the proposed expression giving $N u_{c a l c}$, is defined by the following expression:

$$
N u_{\text {calc }}=0,032 \cdot \mathrm{Re}^{0,8} \cdot S t^{0,3} \cdot\left(1+\left(\frac{D_{i}}{z}\right)^{0,7}\right) \cdot\left(\frac{m_{c} \cdot C_{p_{c}}}{m_{h} \cdot C_{p_{h}}}\right)
$$

with the Reynolds number defined by:

$$
\operatorname{Re}=\frac{v_{g} \cdot D_{h}}{v_{g}}
$$

with $D_{h}$ the hydraulic diameter ( $D_{h}=\frac{4 A}{P}$ with $A$ the cross-section the gaseous flow and $P$ the perimeter of $A$ ) and $v_{g}$ the cinematic viscosity depending on the hot gases temperature. The Nusselt correlation is established by the interpolation of the experimental data for a flows regime. The constant equal to 0.032 is obtained after the interpolation and setting the ratios and the exponents. Then, a checking step is performed in order to validate for the others flows regimes. 
The validation of this suggested correlation, shown in the figure 8 , is based on its comparison with the experimental $N u$ numbers. The experimental $N u$ numbers are obtained by means of the measurements of $h_{i}$ performed on the large scale HMA plant and described in section 2. The experimental $\mathrm{Nu}$ numbers are defined according to the explanation of the end of the section 3 as follows from the formula (10), by using the mass flow rate of each phase flowing within the baffled-rotary kiln monitored in the real HMA plant:

$$
N u_{\text {exp }}=\frac{h_{i} \cdot \pi \cdot D_{i}}{\frac{1}{m_{g}+m_{a}}\left(m_{g} \cdot \lambda_{g}+m_{a} \cdot \lambda_{a}\right)}
$$

The weighing of the thermal physical properties by its respective mass flow rate takes into account the composition of the multiphase flow and its heat transfer pattern with the drum wall, mentioned in the end of the section called granular motion at the pilot-scaled drum.

The results are shown in the figure 10, together with the experimental values and the calculated values. The calculated $N u$ numbers are achieved by using the mass flow rate of each phase flowing within the baffled-rotary kiln issued from the monitoring of the HMA plant. The figure 8 presents the experimental $N u$ numbers and the calculated $N u$ numbers in the HMA plant running conditions. The chart is plotted in dimensionless numbers in such way, that the length of the drum is divided by its diameter.

As it can be seen from the previous figure, the calculated Nusselt numbers are in good agreement with the measured Nusselt numbers. The measured Nusselt numbers ranged between 99 to 1070 , and those of the calculated Nusselt numbers are ranged from 110 to 830 . The relative mean deviation is equal to $23 \%$. This indicator decreases to $17 \%$ if the measurements located after the RMI $\left(z / D_{i}=1.65\right)$ are disqualified for the relative mean deviation calculation because of the aero-dynamical disturb caused by the air jet penetrations. 
Theses observations confirm that this correlation seems to be relevant for the evaluation of the wall heat transfer in the baffled-rotary kiln.

\section{Conclusion}

In the present paper, a correlation of the wall heat transfer is proposed in baffledrotary kiln. The major results are based on thermal experimental data processed from a largescale rotary kiln applied to the drying and heating of mineral components.

- The experimental results [16] are analyzed in terms of the hot and cold mass fluxes proving that a secondary flow, connected to a recycled materials inlet (RMI), is responsible to the wall cooling. It contributes to the augmentation of the wall heat transfer coefficient corresponding to the heat exchange between the multi-phases flow (including the particulate system and the freeboard gases) and the inner wall of the drum.

- From these last results, a physical model is suggested within the rotary kiln based on the ratio of the cold mass flow rate and the hot mass flow rate, balanced respectively by their specific heat:

$$
\text { before RMI: } \frac{m_{c} \cdot C_{p_{c}}}{m_{h} \cdot C_{p_{h}}}=\frac{m_{a} \cdot C_{p_{a}}}{m_{g} \cdot C_{p_{g}}}
$$

$$
\text { after RMI: } \frac{m_{c} \cdot C_{p_{c}}}{m_{h} \cdot C_{p_{h}}}=\frac{m_{a} \cdot C_{p_{a}}+m_{o a} \cdot C_{p_{o a}}}{\dot{m}_{g} \cdot C_{p_{g}}}
$$

- Visualization carried out at the pilot-scale rotary yielded the granular transversal distribution composed of $4 \%$ of aerated phase, the rest of the granular assembly being located in a bed at the bottom of the drum. Thus, the particulate system has not to be considered as homogeneously dispersed in the cross-section of the rotary drum. Consequently, it is 
necessary to distinguish two transfer pathways: (i) the heat transfer between the gases and the inner wall of the drum, (ii) the heat transfer between the granular bed and the drum wall. And so, for the determination of the inner wall heat transfer coefficient, the thermal physical properties of the multi-phase flow are weighted by each mass flow rate composing this multiphase flow.

- Finally, a continuous formula inspired to the heat transfer literature [17] is proposed substituting the Prandtl number by the Stanton number, which is more relevant for that application. Indeed, the wall heat transfer path involves the drum wall and the multi-phases flow and requires the utilization of the ratio between the thermal cold fluxes and the thermal hot fluxes to yield the following wall heat transfer correlation:

$$
N u=0,032 \cdot \operatorname{Re}^{0,8} \cdot S t^{0,3} \cdot\left(1+\left(\frac{D_{i}}{z}\right)^{0,7}\right) \cdot\left(\frac{m_{c} \cdot C_{p_{c}}}{m_{h} \cdot C_{p_{h}}}\right)
$$

The validation of this correlation is assessed from four typical measurements performed at large-scale. The relative mean deviation is equal to $23 \%$ in the whole of the baffled-rotary drum, and declined to $17 \%$ for data extracted after the RMI.

\section{Acknowledgement}

The authors would like to express their thanks to Ermont-Fayat Group for the financial fund for the thermal rod instrumentation. The authors are grateful to the SEMR / CETE Normandie-Centre department for the monitoring of the industrial mix-asphalt processing unit.

\section{Références}


[1] Geng F., Li Y., Yuan L., Wang, X., Yuan Z., Yan Y., Luo D., Experimental study on the space times of flexible filamentous particles in a rotary dryer, Experimental Thermal and Fluid Science 44 (2013) 708-715.

[2] Descoins N., Dirion J.-L., Howes T., Solid transport in a pyrolysis pilot-scale rotary kiln: preliminary results_-stationary and dynamic results, Chemical Engineering and Processing: process intensification 442 (2005) 315-321.

[3] Suzuki T., Okazaki T., Yanamoto K., Nakata H. and Fujita O., a. Improvements in pyrolysis of Wastes in an externally heated rotary kiln (Measurements of the overall heat transfer coefficient from the wall to wastes), Journal of Thermal Science and Technology 33 (2008) $523-531$.

[4] Debacq M., Vitu S, Ablitzer D., Houzelot J.L., Patisson F., Transverse motion of cohesive powders in flighted rotary kilns: Experimental study of unloading at ambient and high temperatures, Powder Technology (2013), doi: 10.1016/j.powtec.2013.04.007.

[5] Hobbs A., Simulation of an aggregate dryer using coupled CFD and DEM methods, International Journal of Computational Fluid Dynamics 232 (2009) 199-207.

[6] Tscheng S.H., Watkinson A.P., 1979, Convective heat transfer in a rotary kiln, Canadian Journal of Chemical Engineering, 574 433-443.

[7] Herz F., Iliyan M., Specht E., Stanev R., Influence of operational parameters and material properties on the contact heat transfer in rotary kilns, International Journal of Heat and Mass Transfer 55 (2012) 7941-7948.

[8] Gorog J.P., Adams T.N., Brimacombe J.K., Heat transfer from flames in a rotary kiln, Metallurgical Transfer B, 14 B (1983) 411-424.

[9]Lehmberg J., Hehl K., Schugerl K., Transverse mixing and heat transfer in horizontal rotary drum reactors, Powder Technology 18 (1977) 149-163. 
[10] Lisboa M.H., Vitorino D.S., Delaiba W.B., Finzer J.R.D., Barrozo M.A.S., A study of particle motion in rotary dryer, Brazilian Journal of Chemical Engineering 2403 (2007) 365374.

[11] Vargas W. L., Hajra S. K., Shi D., McCarthy J. J., Suppressing the Segregation of Granular Mixtures in Rotating Tumblers, AIChE 5412 (2008) 3124-3132.

[12] Miller C.O., Smith B.A., Schuette, Factor influencing the operation of rotary dryers, Trans AIChE 38 (1942) 841.

[13] Thammavong P., Debacq M., Vitu S., Dupoizat M., Experimental Apparatus for studying heat transfer in externally heated rotary kilns, Chemical Engineering Technology 345 (2011) $707-717$.

[14] Suzuki T., Okazaki T., Yanamoto K., Nakata H. and Fujita O., b. Improvements in pyrolysis of Wastes in an externally heated rotary kiln (Experimental study on heat transfer enhancement), Journal of Thermal Science and Technology 33 (2008) 532 -539.

[15] Schlunder E.U., Heat transfer to packed and stirred beds from the surface of immersed bodies, Chemical Engineering and processing: process intensification 18 (1984) 31-53.

[16] Le Guen, Huchet F., Dumoulin J., Baudru Y., Tamagny P., Convective heat transfer analysis in aggregates rotary drum reactor, Journal of Applied Thermal Engineering 54 (2013) 131-139.

[17] Colburn A.P., A method of correlating forced convection heat transfer data and a comparison with fluid friction, Journal of American Institute of Chemical Engineers 29 (1933) 174-210.

[18] McAdams W.H., Heat transmission. Ed. Mc Graw Hill Book Compagny, New York, 1954. 
[19] Dumoulin J., Marchand M., Reulet P., Millan P., Heat transfer identification induced by multiholes cooling in combustion chambers, Quantitative Infrared Thermography congress (1996), Stuttgart, Germany.

[20] Léger B., Miron P., Emidio J.P., Geometric and aero-thermal influences on multiholed plate temperature: application on combustion wall, International Journal of Heat and Mass Transfer 46 (2003) 1215-1222.

[21] Raznjevic K., Tables et diagrammes thermodynamiques, Eyrolles Editeur Paris, 1970.

[22] White F.M., Heat and mass transfer, Addison-Wesley publishing company (1984), p. 588

[23] Huang Q., Zhang H., Zhu J., Experimental study on fluidization of fine powders in rotating drums with various wall friction and baffled rotating drums, Chemical Engineering Science 653 (2010) 1261-1273.

[24] Henein H., Brimacombe J., Watkinson A.P., The modeling of transverse solids motion in rotary kilns. Metallurgical Transactions B, 14B (1983) 207-220.

[25] Image J: soft loading address: http://rsb.info.nih.gov/ij/

[26] Debacq M., 2001, Etude et modélisation des fours tournants de défluoration et réduction d'uranyle, Ph.D. thesis, Institut National Polytechnique de Lorraine, France.

[27] Le Guen L., 2012, Etude des aspects énergétiques de la fabrication des enrobés bitumineux en centrale d'enrobage, Ph.D. thesis, Ecole Centrale de Nantes, France. 


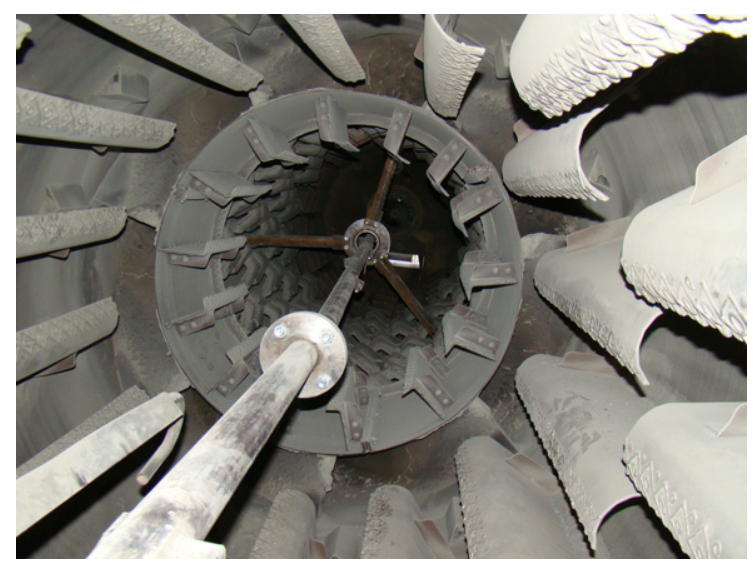

Figure 1 - View of an empty rotary drum used in the Hot-Mix-Asphalt (HMA) plant and equipped with the probes rod. 


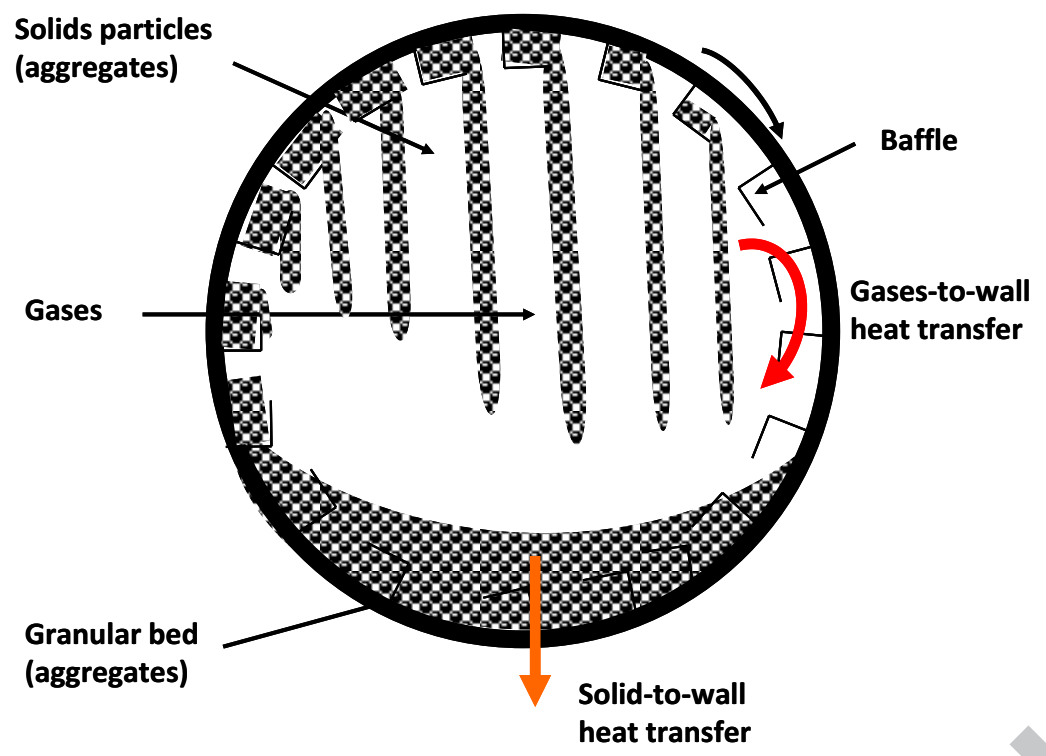

Figure 2 - Rotary drum cross-section describing solid-to-wall heat transfer and gases-to-wall heat transfer in the baffled-rotary kiln. 


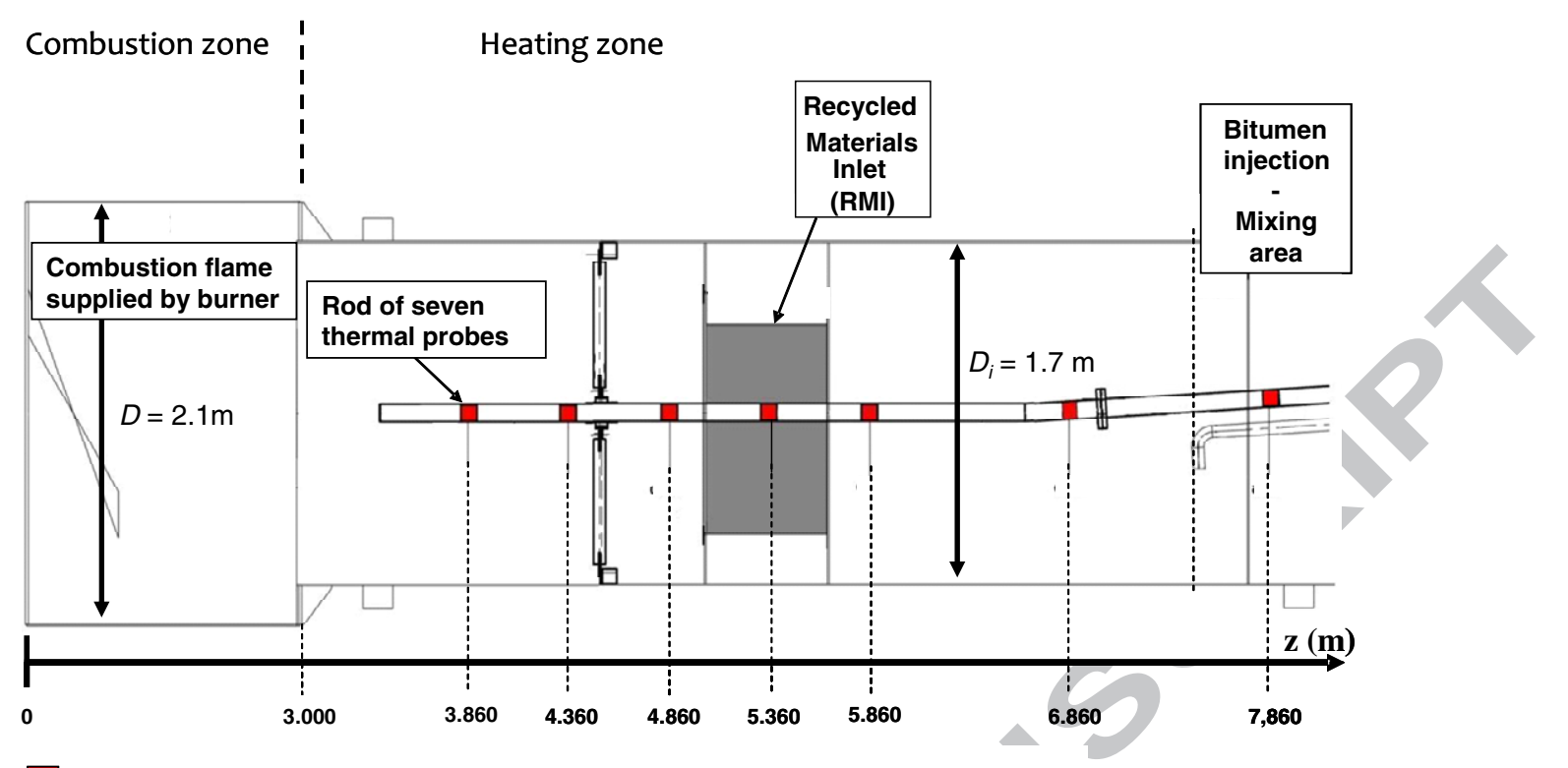

Tg (K-type)

Figure 3 - Scheme of the rotary kiln set-up. 

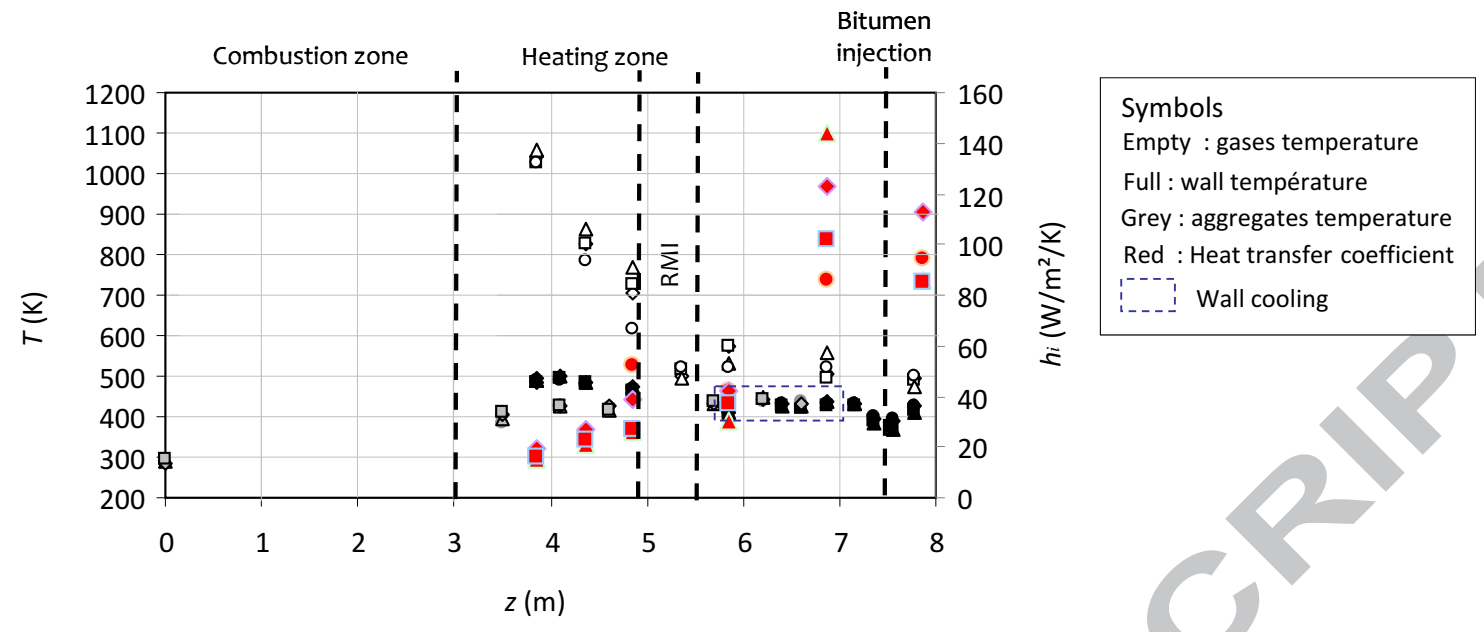

Figure 4 - Longitudinal temperatures and heat transfer coefficient measured in large-scale kiln at different aggregates feed rate \{Circle : $m_{a}=26 \mathrm{~kg} \cdot \mathrm{s}^{-1}$ - Triangle : $m_{a}=29 \mathrm{~kg} \cdot \mathrm{s}^{-1}-$ Diamond : $m_{a}=31 \mathrm{~kg} . \mathrm{s}^{-1}$ - Square : $\left.m_{a}=34 \mathrm{~kg} \cdot \mathrm{s}^{-1}\right\}$. 


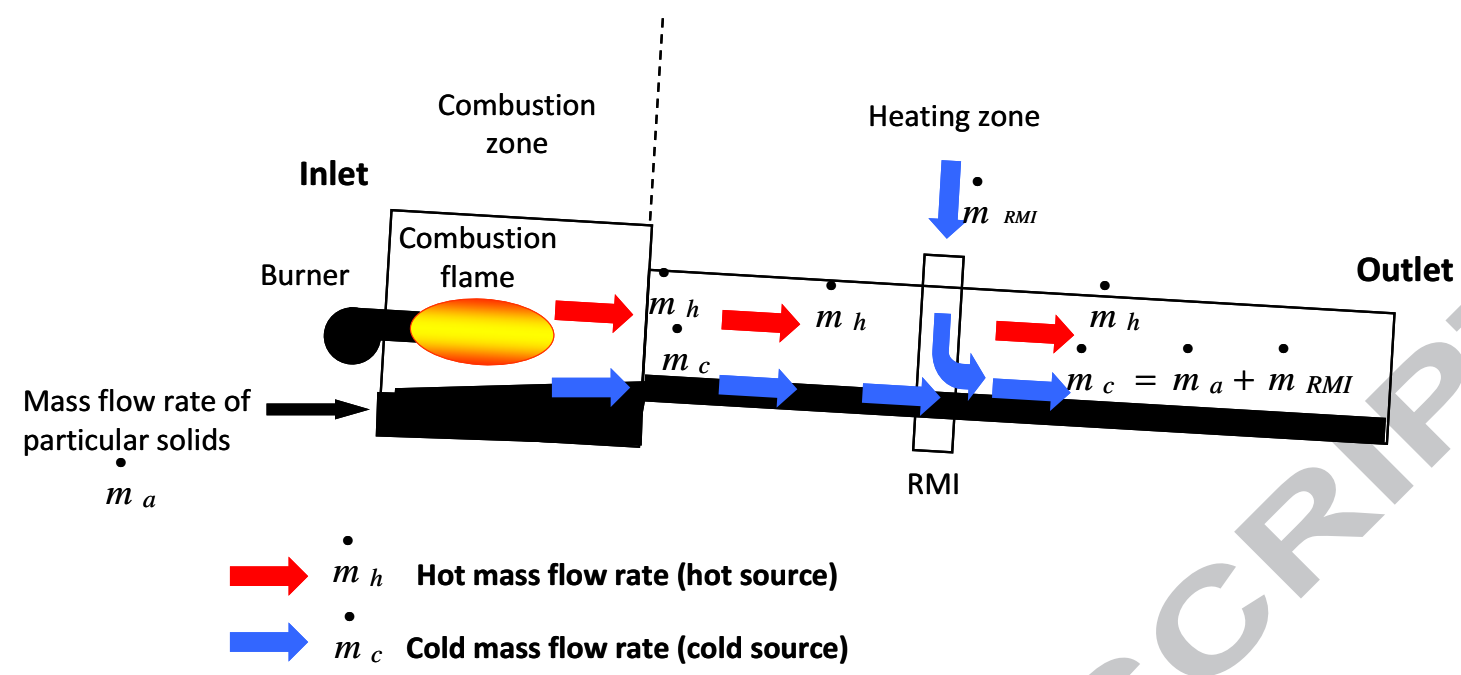

Figure 5 - Scheme describing the different flow paths encountered in the rotary kiln. 


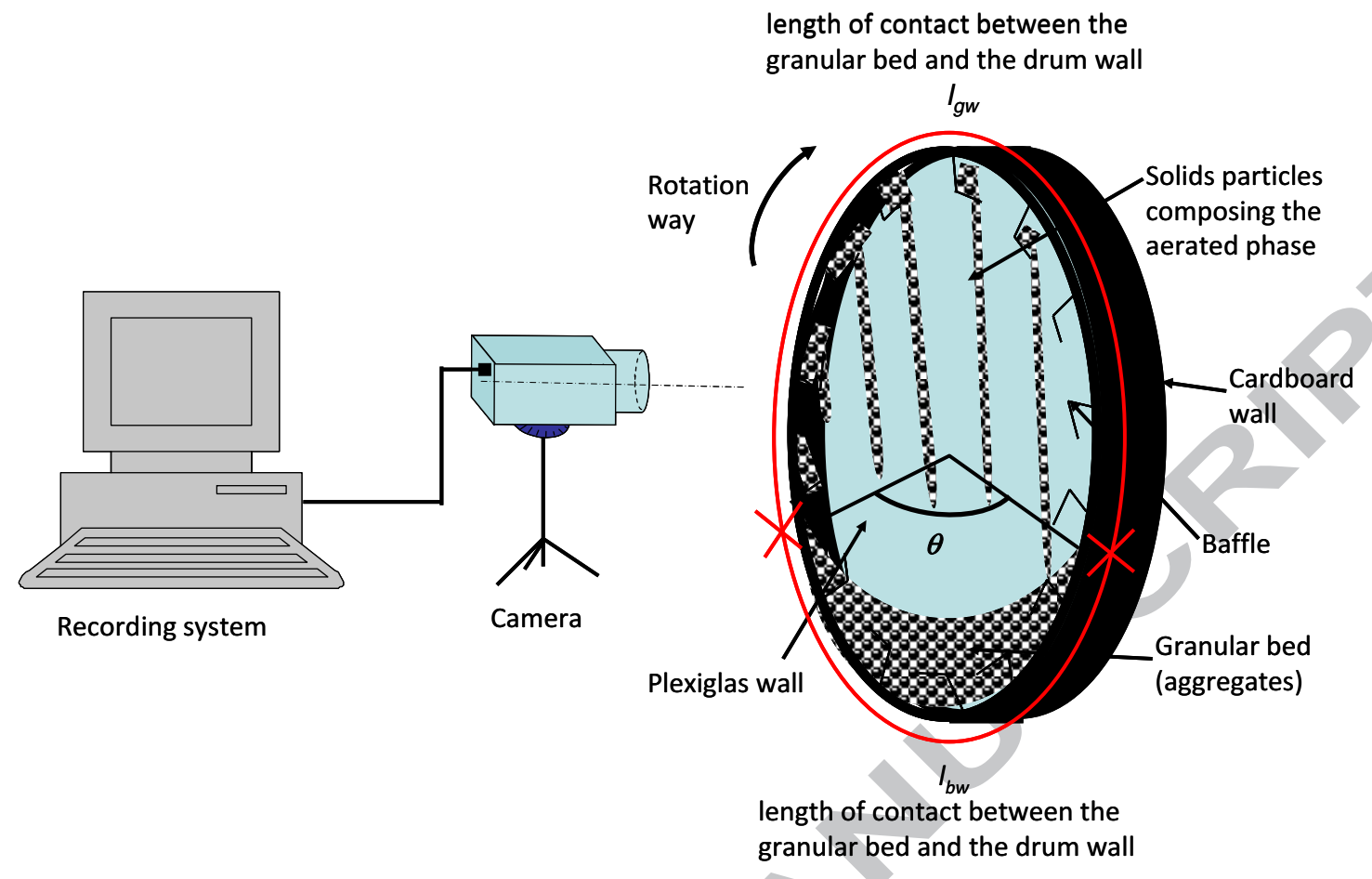

$\boldsymbol{\theta}:$ Angle defined the two apexes of the granular bed

Figure 6 - Scheme of the visualization set-up. 

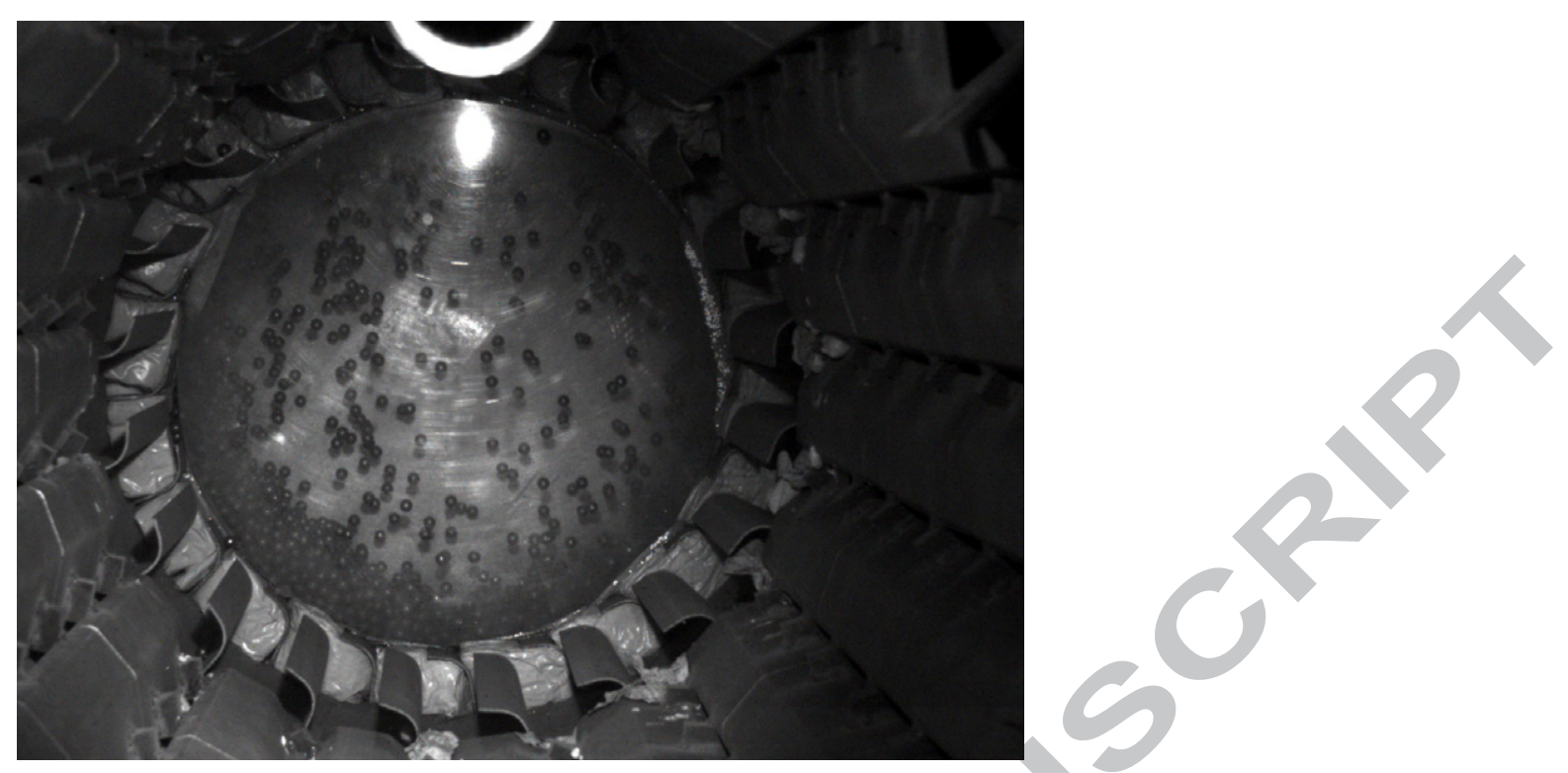

Figure 8 - Typical image of the dynamic behavior of the steel beads in the pilot-scale rotary drum of pilot-scaled HMA rotary drum. 


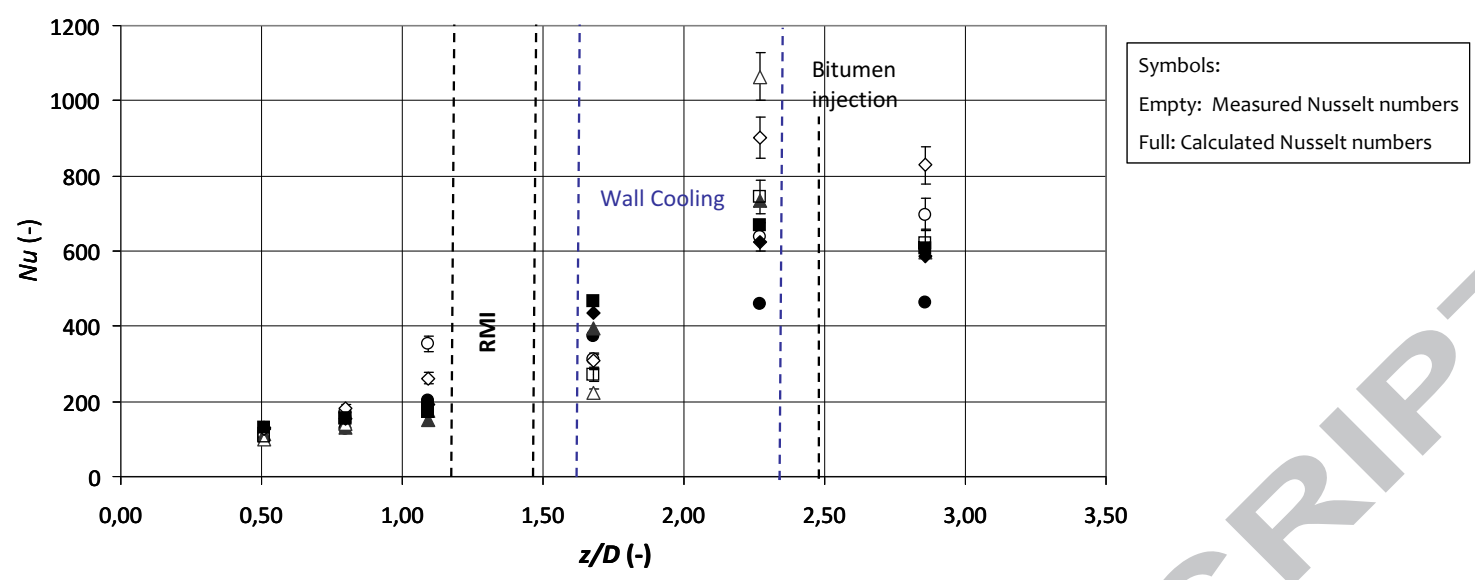

Figure 8 - Calculated and measured Nusselt numbers describing the inner parietal heat transfer in the heating zone measured in large-scale kiln at different aggregates feed rate \{Circle : $m_{a}=26 \mathrm{~kg} . \mathrm{s}^{-1}$ - Triangle : $m_{a}=29 \mathrm{~kg} \cdot \mathrm{s}^{-1}$ - Diamond : $m_{a}=31 \mathrm{~kg} \cdot \mathrm{s}^{-1}$ - Square : $m_{a}=34$ $\left.k g \cdot s^{-1}\right\}$.

A new correlation is proposed to obtain the inner parietal heat transfer coefficient applied to a baffled rotary drum.

A previous work (Le Guen et al., 2013) is completed with the new observations about this work and the measurements performed on pilot scale experimental campaign.

On this basis, several modifications (the Stanton number and the ratio between the cold and hot mass flow rates weighted by its specific heat respectively ) of the Nusselt correlation of Colburn (1933) are proposed in order to respect the specificities of the baffled-rotary kiln with the secondary air flow and recycled materials.

The results are in a good agreement with the experimental values. 